OPEN ACCESS

Edited by:

Christina Peters,

St. Anna Children's Cancer Research Institute (CCRI), Austria

Reviewed by:

Lena Oevermann

Charité-

Universitätsmedizin Berlin, Germany

Feng Chen,

The First Affiliated Hospital of

Soochow University, China

*Correspondence:

Hany Ariffin

hany@ummc.edu.my

Specialty section:

This article was submitted to

Pediatric Hematology and

Hematological Malignancies,

a section of the journal

Frontiers in Pediatrics

Received: 14 August 2021 Accepted: 30 September 2021

Published: 21 January 2022

Citation:

Ab Rahman S, Matic T, Yordanova M and Ariffin H (2022)

HLA-Haploidentical Family Donors: The New Promise for Childhood Acute

Lymphoblastic Leukaemia?

Front. Pediatr. 9:758680.

doi: 10.3389/fped.2021.758680

\section{HLA-Haploidentical Family Donors: The New Promise for Childhood Acute Lymphoblastic Leukaemia?}

\author{
Syaza Ab Rahman ${ }^{1}$, Toni Matic ${ }^{2}$, Maya Yordanova ${ }^{3}$ and Hany Ariffin ${ }^{1 *}$ \\ ${ }^{1}$ Paediatric Haematology-Oncology and Bone Marrow Transplantation Unit, University of Malaya Medical Centre, Kuala \\ Lumpur, Malaysia, ${ }^{2}$ Department of Paediatrics, University Hospital Centre, Zagreb, Croatia, ${ }^{3}$ Children's Oncohematology \\ Unit, Queen Johanna University Hospital, Sofia, Bulgaria
}

Allogeneic haematopoietic stem cell transplantation (HSCT) is indicated in children with high-risk, relapsed or refractory acute lymphoblastic leukaemia (ALL). HLA-matched grafts from cord blood and stem cell repositories have allowed patients without suitable sibling donors to undergo HSCT. However, challenges in procuring matched unrelated donor (MUD) grafts due to high cost, ethnic disparity and time constraints have led to the exponential rise in the use of stem cells from human leukocyte antigen (HLA)-haploidentical family donors. Whilst HLA-haploidentical HSCT (hHSCT) performed in adult patients with acute leukaemia has produced outcomes similar to MUD transplants, experience in children is limited. Over the last 5 years, more data have emerged on hHSCT in the childhood ALL setting, allowing comparisons with matched donor transplants. The feasibility of hHSCT using adult family donors in childhood ALL may also address the ethical issues related to selection of minor siblings in matched sibling donor transplants. Here, we review hHSCT in paediatric recipients with ALL and highlight the emergence of hHSCT as a promising therapeutic option for patients lacking a suitable matched donor. Recent issues related to conditioning regimens, donor selection and graft-vs.-host disease prophylaxis are discussed. We also identify areas for future research to address transplant-related complications and improve post-transplant disease-free survival.

Keywords: haploidentical, haematopoietic stem cell transplantation, paediatric, acute lymphoblastic leukaemia (ALL), human leukocyte antigen

\section{BACKGROUND}

Allogeneic haematopoietic stem cell transplantation (HSCT) is used to consolidate remission in patients with genetic subtypes of childhood acute lymphoblastic leukaemia (ALL) at high risk of relapse as well as those with relapsed or refractory disease. For the latter two groups, immunotherapy such as anti-CD19 antibodies as well as chimeric antigen receptor (CAR) T cells have been utilised. However, these new immunotherapy modalities are relatively expensive and not universally available. Notably, immunotherapy has not completely removed the need for HSCT in patients with relapsed or refractory ALL.

Currently, human leukocyte antigen (HLA)-matched sibling donors (MSDs) are the preferred choice for children with ALL who need to undergo HSCT for disease control (1). However, sibling pairs have only a $25 \%$ chance of inheriting the same HLA haplotype; thus, volunteer donor stem 
cell and umbilical cord blood registries have been established to provide an alternative source of HLA-matched donor grafts.

Banked cryopreserved umbilical cord blood units allow greater mismatching degree and are easily available with faster procurement. Studies have demonstrated the benefits of umbilical cord blood transplantation in paediatric haematologic malignancies where cord blood cell dose and HLA-grade matching are crucial factors for transplant outcome (2-4). However, umbilical cord blood transplantation still carries high risks of graft failure, delayed engraftment and slower immune reconstitution. Additionally, with single umbilical cord blood units, there is no source for subsequent stem cell boost or other cell-based therapies (4).

Despite the availability of international stem cell repositories, challenges in procuring matched unrelated donor (MUD) grafts due to high costs, ethnic disparity and time constraints have led to the exponential rise in the use of stem cells from HLAhaploidentical family donors, reflected in registry data of the last decade (5). HLA-haploidentical HSCT (hHSCT) allows immediate and almost universal family donor availability (HLAmatched at 8 out of 10 loci or less) at lower cost and easier accessibility than MUD and so has expanded curative options for many ALL patients with urgent transplant indications.

Currently, hHSCT can be performed using either manipulated or unmanipulated grafts with various strategies to eliminate prohibitive graft-vs.-host disease (GvHD). For manipulated donor marrow or peripheral blood grafts, ex-vivo T-cell depletion is performed using sophisticated cell sorting machines which remove immune cell subsets that cause GvHD (TCR $\alpha \beta$, $\mathrm{CD}_{5} \mathrm{RA}^{+}, \mathrm{CD} 19^{+}$depletion). Conversely, subsets that provide graft-vs.-leukaemia (GVL) effect namely TCR $\gamma \delta$ T cells as well as NK cells, monocytes and dendritic cells which promote prompt immune reconstitution are retained.

A technically simpler platform comprises an unmanipulated graft with in vivo depletion of alloreactive $\mathrm{T}$ cells and highdose post-transplant cyclophosphamide (PTCy). The hHSCTPTCy technique-pioneered by researchers from Johns Hopkins University (6) -is widely applied clinically and has substantially extended the use of hHSCT in patients with acute leukaemia. Another method is the Beijing "GIAC" protocol, developed by Huang et al. This comprises granulocyte colony-stimulating factor (G-CSF)-primed donor peripheral blood and marrow stem cells and intensive immunosuppression using mycophenolate mofetil (MMF), cyclosporine A (CsA), methotrexate and antithymocyte globulin (ATG) (7).

Here, we review the hHSCT experience for children with ALL and discuss the development of hHSCT as a promising therapeutic option for those lacking an HLA-matched donor.

\section{IMMUNOBIOLOGY CONSIDERATIONS IN HSCT}

HLA diversity is the cornerstone of "self" vs. "foreign" recognition in the immune system. The biological role of HLA class I and class II molecules is to present processed peptide antigens to immune cells for non-self recognition and killing. HLA mismatch between a recipient and a stem cell donor represents a bi-directional risk factor for both GvHD and graft rejection (host-versus-graft). GvHD is caused by immunocompetent donor $\mathrm{T}$ cells contained in the stem cell graft. In hHSCT, several methods have been developed to deplete alloreactive donor $\mathrm{T}$ cells with the goal of averting or minimising GvHD. However, although efficient T-cell depletion of donor marrow leads to a lower incidence of acute GvHD, a higher incidence of graft failure, leukaemia relapse and delayed immune reconstitution may result (8). Graft rejection in this instance is mediated by recipient cytotoxic T lymphocyte precursors that survive the conditioning regimen, along with anti-donor HLA antibodies $(9,10)$. Although markedly reduced by pre-transplantation conditioning chemotherapy or radiation, residual recipient immune cells are often adequate to mount a response against a graft that is "unprotected" by donor immune cells. Thus, a successful hHSCT outcome requires a nuanced immunological balance between the haploidentical graft and recipient.

$\mathrm{T}$ cells play a central role in the pathophysiology of both GvHD and the GVL effect. A key event in the development of acute GvHD is the interaction of $\mathrm{T}$ cells expressing a suitable T-cell receptor with antigen-presenting cells that express host major histocompatibility complex or minor histocompatibility antigen peptides. Activated $\mathrm{CD} 8^{+}$T-cytotoxic and $\mathrm{CD} 4^{+} \mathrm{T}$ helper (Th)1, Th2, and Th17 cells can directly cause GvHD via release of cytolytic cytokines such as perforin or tumour necrosis factor alpha (11). Additionally, co-stimulatory pathways such as CD40 ligand (12) and programmed death 1 and programmed death ligand 1 (PD-L1) (13) - key cytokines that influence Tcell differentiation as well as metabolic pathways that provide energy for T-cell proliferation (14)-contribute to overlapping mechanisms that promote GvHD. In gut GVHD, intestinal tissue damage from conditioning therapy results in the recruitment of innate immune cells to the injured tissue and release of damageassociated molecular pattern (DAMP) molecules. Infiltration of neutrophils and monocytes into the gastrointestinal tract causes activation and production of reactive oxygen species that contribute directly to tissue damage. DAMP molecules enhance GVHD through cleavage of precursor intracellular cytokine pro-interleukin- $1 \beta$ into its bioactive form by caspase- 1 or caspase-11, and through the transcription of genes that encode cytokines and chemokines that promote GVHD. Inflammatory responses may also be induced by infectious pathogens that trigger the release of pathogen-associated molecular pattern (PAMPs) molecules. These molecules activate innate immune cells that migrate from damaged intestinal epithelium to mesenteric lymph nodes for antigen presentation and donor $\mathrm{T}$ cell activation (14).

Recently, two groups $(15,16)$ have proposed a novel mechanism of GvHD pathophysiology. Using single-cell analysis, Jardine et al. demonstrated that acute GvHD can result from peripheral host $\mathrm{T}$ cells resident in the skin and gut being stimulated against donor antigen-presenting cells in the form of monocyte-derived macrophages. These donor-derived macrophages have enhanced antigen-presenting functions that could enable the activation of residual host $\mathrm{T}$ cells, resulting 
in host-vs.-graft responses that may be indistinguishable from GvHD clinically (16). Divito et al. reported similar findings of host peripheral $\mathrm{T}$ cells in skin GvHD specimens (15). They developed a humanised mouse model of skin GvHD where skin-resident host $\mathrm{T}$ cells were activated by donor monocytes (15).

$\mathrm{CD}^{+} / \mathrm{CD} 25^{+} / \mathrm{Foxp}^{+}$regulatory $\mathrm{T}$ cells (Tregs) play a protective role by downregulating the immune response when it is no longer needed, thus maintaining immune homeostasis. Tregs suppress the immune response in several ways, including: (1) producing anti-inflammatory cytokines such as transforming growth factor (TGF)-b and interleukin (IL)-10; (2) suppressing activation and proliferation of both T-helper and T-cytotoxic cells; and (3) suppressing B cells and dendritic cells. Memory $\mathrm{CD}_{45 \mathrm{RO}^{+}}$Tregs do not express the bone marrow homing receptor CXCR4; thus, few donor Tregs migrate to the host marrow $(17,18)$. The lack of donor Tregs in the marrow allows for unopposed conventional T-cell alloreactivity and is the basis for the GVL effect.

NK cells are regulated by a number of receptors that finely tune potent effector functions including cytolytic activity against different target cells and release of cytokines that play a major role in inflammation and immunoregulation. NKcell education or licencing facilitates a balance between selftolerance under physiologic conditions and maintenance of the ability to mediate an immune response against microbial pathogens and leukaemia cells (19). The role of natural killer (NK) cells in the pathogenesis of GVHD is still controversial. The conventional view is that, in contrast to $\mathrm{T}$ cells, alloreactive NK cells protect against GvHD. Normal recipient tissues that are common targets of T-cell-mediated GvHD, such as skin and gut mucosa, are spared due to lack of ligands for activating NK-cell receptors. Donor NK cells can also eliminate recipient-type antigen-presenting cells, a process that is based on mismatches of killer-cell immunoglobulin-like receptors (KIR), thus preventing presentation of host antigens to graft $\mathrm{T}$ cells. However, several recent studies have revealed that whilst NK cells naturally suppress GVHD, highly pre-activated NK cells can induce donor T-cell alloreactivity through the production of proinflammatory cytokines such as TNF- $\alpha$ and IFN- $\gamma(20)$.

NK-cell alloreactivity is especially useful in the setting of HLA-mismatched transplants, where NK cells exert antileukaemic activity without concomitant GvHD (21). In HLAmismatched HSCT for acute myeloid leukaemia (AML), NKcell alloreactivity has been shown to decrease the risk of relapse while enhancing engraftment and reducing GvHD by eliminating host dendritic cells (22). More recently, improved understanding of NK cell biology has led to the use of KIR-ligand mismatched donors to enhance the GVL effect in patients undergoing HSCT for haematologic malignancies $(23,24)$.

The goal of hHSCT is to optimally manipulate immune cells of both the host and donor to achieve stable engraftment, immune reconstitution with adequate GVL effect and protection against infections, while simultaneously achieving immune tolerance which affords acceptable GvHD.

\section{hHSCT IN THE TREATMENT OF HAEMATOLOGICAL MALIGNANCIES}

hHSCT has been utilised in the management of patients with haematological malignancies for over 30 years. In the 1990's, a group in Perugia successfully demonstrated a method to overcome the immunological barrier in hHSCT through the infusion of "megadose" T-cell-depleted progenitor cells after high-intensity conditioning in adults with acute leukaemia (25). The method was associated with high engraftment rates and minimal GvHD but a high incidence of non-relapse mortality (NRM) and relapse rates (26). Over time, optimization of the conditioning regimen and evolving graft processing techniques for modulation of T-cell alloreactivity have alleviated the main challenges for transplantation across the HLA barrier, i.e., graft rejection, GvHD and unacceptably high treatment-related toxicity (TRM).

\section{T-Cell-Depleted hHSCT}

Introduction of refined, partial T-cell-depletion methods $(\alpha \beta$ depleted hHSCT) has considerably improved post-transplant immune reconstitution as well as anti-infective and antileukaemia (GVL) activity, resulting in outcomes comparable to MSD and MUD transplants (27-30).

In a single-centre cohort of 80 children with ALL in remission, Locatelli et al. reported a disease-free survival (DFS) of $71 \%$ using TCR $\alpha \beta$ T-cell- and CD19-depleted hHSCT following myeloablative conditioning with ATG, comparable to DFS with transplants using MSD or MUD grafts (30). Another Italian multicentre study that involved 98 children with leukaemia who underwent TCR $\alpha \beta$ T-cell- and CD19-depleted hHSCT following myeloablation presented a 5-year probability of leukaemia-free survival (LFS) of 62\%, with chronic GvHDfree/relapse-free survival (GRFS) outcomes comparable to those of MUD transplants and superior to mismatched unrelated donor (MMUD) transplants (27). Lang et al. reported encouraging results for children with leukaemia in first complete remission (CR1) to CR3 using TCR $\alpha \beta$ T-cell- and CD19-depleted hHSCT following myeloablation (1-year EFS of 100\%), although no patients with active disease survived (29). This group also showed the successful use of TCR $\alpha \beta$ T-cell- and CD19-depleted hHSCT following reduced-intensity conditioning (RIC) in a study of 30 patients, including 10 patients with ALL (31). Good outcomes using T-cell-depleted hHSCT were also reported by Shelikhova et al. in paediatric ALL patients; the probability of 2-year EFS was $49.6 \%$ and 2-year OS was 50\%) (32). A Turkish study in paediatric acute leukaemia patients showed that the survival of patients with high-risk acute leukaemia after TCR $\alpha \beta$ T-celland CD19-depleted hHSCT with use of ATG and mesenchymal stem cells was comparable to MUD transplantation (28). Jacoby et al. reported an EFS of $61 \%$ in children with leukaemia using total body irradiation (TBI)-based conditioning and $\alpha \beta$ T-cell-depleted hHSCT (33). Recently, the ALL SCT BerlinFrankfurt-Münster (BFM) Study Group conducted a study with 569 children with very-high-risk ALL who received HSCT. Among them, 106 patients had a graft from a mismatched donor and 62 of them received an ex vivo T-cell-depleted 
peripheral blood stem cell graft either by positive $\mathrm{CD} 34^{+}$ selection or by negative $\mathrm{CD} 3^{+} / \mathrm{CD} 19^{+}$depletion. The 4 -year EFS was statistically better for patients transplanted from matched compared with mismatched donors and this was attributed to a lower NRM (1).

\section{T-Cell Replete hHSCT With PTCy}

The PTCy method of hHSCT has been used with both RIC and myeloablative conditioning regimens and also using either blood or marrow stem cells. In the original PTCy-based protocol published by the John Hopkins University group, the use of RIC with PTCy after bone marrow transplantation was associated with acceptable incidences of graft failure and GvHD but a high risk of relapse (6). There is limited data to estimate the efficiency and safety of hHSCT using unmanipulated grafts in the paediatric setting and results from larger studies of adult patients with ALL may not be accurate to extrapolate to children. In several small series of T-cell-replete hHSCT in high-risk paediatric ALL patients, acceptable rates of GvHD and NRM with effective and rapid immune reconstitution have been reported $(34,35)$.

The first study in a paediatric-only cohort was from Japan and comprised 15 children with advanced leukaemia (36). Both bone marrow and peripheral blood grafts were used. CR was achieved in $46 \%$ of the patients but long-term outcome was poor. A high incidence of grade III-IV GvHD (25\%) was reported and this was attributed to the use of RIC and singleday cyclophosphamide $($ day +3$)$ as opposed to two doses. Klein et al. studied the use of RIC in children and young adults with haematological malignancies, including ALL, and found a low NRM rate but a high cumulative incidence of relapse $52 \%$ at 2 years) (37). Majority of patients received bone marrow graft and two patients received peripheral blood graft. Another recent study by Trujillo et al. reported on 42 children with highrisk malignancies (22 with ALL) who underwent hHSCT-PTCy with RIC (fludarabine plus busulfan or melphalan, and low-dose TBI) and peripheral blood as the stem cell source (38). The group demonstrated outcomes comparable to studies utilising myeloablative regimens, with 1-year TRM of $14 \%$, a relapse rate of $26 \%$, 3-year OS of $56 \%$, and 3-year EFS of $46 \%$. However, a high incidence of moderate-to-severe GvHD was seen in younger children, with $40 \%$ of those $<10$ years of age experiencing grade III-IV GvHD. In a retrospective study comparing hHSCT-PTCy to HSCT using an MUD or MMUD after RIC in paediatric patients with acute leukaemia, a group in Italy reported similar outcomes with regards to 5-year OS, NRM and relapse incidence between the three groups (39).

A myeloablative preparative regimen followed by hHSCTPTCy using peripheral blood stem cells was used in 20 children with advanced leukaemias. The 2-year OS as reported by Jaiswal et al. was $64.3 \%(40)$. NRM at 1 year was $20 \%$ and this was associated with grade III-IV GvHD (39). Similarly to the study by Trujillo et al., it was noted that high-grade GvHD occurred only in children $<10$ years and there was a higher incidence of early alloreactivity in the form of haemophagocytic syndrome in this age group, findings not previously noted in the adult population. Other studies which have used myeloablation followed by hHSCT-PTCy involving children with ALL were by
Uygun et al. ( $n=60$, Turkey), Yesilipek et al. ( $n=15$, Turkey) and Symons et al. ( $n=96$, USA). The 1-year OS for these children was 64,75 , and $73 \%$, respectively, whilst EFS was 59,68 , and $57 \%$, respectively (41-43). Katsanis et al. conducted a study utilising hHSCT- PTCy - this time in 13 ALL patients who received myeloablation and were negative for minimal residual disease (MRD) prior to hHSCT. With a median follow-up of 25 months, OS was $84.0 \%$ and the GRFS rate was $50.1 \%$ (44).

An Italian study in 33 children with haematological malignancies (15 with ALL) using RIC or myeloablative conditioning mostly with bone marrow stem cell graft reported 1 -year OS of $72 \%$, CIR of $24 \%$, and TRM of $9 \%$ (34). In a similarly designed study by Sharma et al. (17 children with acute leukaemia, median follow-up of 393 days, use of peripheral blood stem cells), OS and EFS were 70.5 and $64.7 \%$, respectively. Of note, three of four children who received RIC relapsed (45).

Recently and on behalf of the European Society of Blood and Marrow Transplantation (EBMT), Ruggeri et al. reported on 180 children with ALL (69\% in CR1 or CR2) who received a preparative regimen of either myeloablative conditioning or RIC (46). The results were promising, with a cumulative incidence of relapse (CIR) of 25.1 and $37 \%$ for those in CR1 and CR2, respectively, and 2-year NRM of $19.6 \%$ for the whole cohort. Cumulative incidence of grade III-IV aGvHD was $12.4 \%$, with a worse outcome in those who received peripheral blood stem cells compared with bone marrow grafts (18.9 vs. $6.2 \%$, respectively; $p=0.04$ ). Disease status was an independent predictor of reduced survival, with 2-year LFS of 65,44 , and $18.8 \%$ in those transplanted in CR1, CR2, and CR3, respectively, and 1-year LFS of $3 \%$ for those transplanted in active disease.

More recently, several groups have adopted modifications to the hHSCT-PTCy approach. Adaptations include earlier initiation of a calcineurin inhibitor (CsA or tacrolimus) on day 0 and MMF on day +1 followed by PTCy on days +3 and $+5(47,48)$. Early administration of a calcineurin inhibitor is thought to spare some donor lymphocytes from the tolerizing effects of cyclophosphamide, thus preserving a GVL effect and reducing the incidence of relapse (49). Previous studies have found this modified approach to be associated with low rates of chronic GvHD and a CIR of about 25\% in adult patients with haematologic malignancies $(47,48)$. The Acute Leukaemia Working Party-EBMT group recently published a retrospective comparative study on the timing of PTCy and immunosuppressive therapy in 509 patients with acute leukaemia. When compared with patients who received PTCy on days +3 and +4 along with CsA/tacrolimus $+\mathrm{MMF}$ on day +5 , the group who received PTCy on days +3 and +5 with early CsA + MMF initiation on days 0 and +1 , respectively, demonstrated significantly better LFS (HR $0.62 ; p=0.02$ ) and GRFS (hazard ratio $[\mathrm{HR}] 0.58 ; p=0.02$ ) primarily due to a lower incidence of relapse (50).

Overall, these recent studies validate the feasibility of the hHSCT-PTCy platform for children with high-risk ALL. The optimal timing for cyclophosphamide administration and the combination of immunosuppressive agents in hHSCT is still unknown, although several studies have shown encouraging outcomes for the modified PTCy approach $(42,47,48,50)$. 


\section{ATG-Based T-Cell Replete hHSCT}

Application of the Beijing "GIAC" hHSCT protocol in 42 children with haematological malignancies was first reported by Liu et al. (51). Outcomes were acceptable, with 3-year LFS of $57.3 \%$, but there were high rates of acute grade IIIV GvHD (57.0\%) and chronic GvHD (56.7\%) (51). Five years later, the same group reported on the efficacy and safety of this transplantation method for children with ALL and acute myeloid leukaemia (AML) in CR1 or CR2 (52). The 5-year LFS for patients with ALL in CR1, CR2 and beyond CR2 or nonremission were $68.9,56.6$, and $22.2 \%$, respectively. In this study, $19 \%$ of cases in CR1 relapsed, whilst NRM was $15 \%$ in CR1/CR2. A large study of 1,210 transplants by Wang et al. included children with ALL (450 patients $<20$ years; $38 \%$ patients with ALL) and reported DFS of $67 \%$ and NRM of $17 \%$ (53). A similar study by Mo et al. using the Beijing protocol in 65 children with high-risk ALL reported a 2-year probability of OS and DFS of 82 and 71\%, respectively (54). Good results with an estimated 3year OS of $69.5 \%$ and DFS of $63.5 \%$ have been noted in children with high-risk Philadelphia chromosome positive $\left(\mathrm{Ph}^{+}\right) \mathrm{ALL}$ managed with this hHSCT protocol $(55,56)$.

Several groups have described other methods of hHSCT without ex-vivo T-cell depletion and using ATG-based GvHD prophylaxis. A study by Ji et al. described the use of ATGbased GvHD prophylaxis with GCSF-primed bone marrow alone, and intensive post-transplant immunosuppression consisting of MMF, CsA, methotrexate, and the addition of anti-CD25 antibody, basiliximab, in 38 patients (both children and adults) with haematological malignancies. Basiliximab is a chimeric monoclonal antibody directed against CD25 present on activated lymphocytes and inhibits IL-2 mediated T cell activation and proliferation, thus reducing the risk of GVHD. The reported 2year DFS was $53 \%$, with low rates of acute grade II-IV GvHD (11\%) and chronic GvHD (15\%) (57). A similar study conducted by an Italian group reported very low rates of advanced and chronic GvHD--at 5 and 6\%, respectively--but with a nonnegligible TRM rate of $30 \%$. The 3 -year OS probability was $45 \%$ (54\% in the standard-risk group, 33\% in the high-risk group) and 3 -year DFS was 38\% (44\% in the standard-risk group, 30\% in the high-risk group) (58).

An innovative approach of combining the Beijing protocol with low-dose PTCy $(14.5 \mathrm{mg} / \mathrm{kg})$ in hHSCT has been reported in 114 patients with haematological malignancies who also had a high risk of post-transplant GvHD (mother or collateral donor). The study reported significantly improved incidences of grade III-IV GvHD ( 5 vs. $8 \%, p=0.003$ ), and improved NRM (6 vs. $15 \%, p=0.045$ ) compared with the original Beijing protocol (59), thus suggesting a synergistic combination of the two modalities.

Different registries have published reports on comparisons of outcomes between PTCy and the Beijing protocol in adult patients with leukaemia. In 2017, the EBMT consortium reported comparable outcomes in relapse rates and OS between PTCy and the Beijing protocol although NRM was lower in the PTCy arm (60). In contrast, the Chinese Bone Marrow Transplantation Registry Group (CBMTRG), reported significantly higher NRM and inferior PFS and OS in hHSCT-PTCy for haematological malignancies compared with G-CSF/ATG (61).
Direct comparison of outcomes using the different hHSCT approaches is difficult as studies in children have mostly involved small numbers of patients and included patients with other diagnoses. A head-to-head study comparing hHSCT using Tcell-depleted or T-cell-replete grafts in children with highrisk haematological malignancies was performed in Uruguay, involving 40 patients (15 with ALL) (62). T-cell-depleted transplants were performed using RIC, while most of those in the T-cell-replete PTCy arm received myeloablation. The results were comparable (actuarial OS rates at 2 years 47 vs. $48 \%$, and 1-year TRM 24 vs. 26\%, respectively, for the T-cell-depleted vs. T-cell-replete PTCy grafts) except for the incidence of chronic GvHD which was significantly higher in the PTCy group (9 vs. $53 \%$, respectively, $p=0.029$ ). In a larger study involving 192 children with high-risk leukaemia, the Spanish Working Group (GETMON/GETH) compared outcomes between hHSCT using PTCy and ex-vivo T-cell depletion. Similar OS, DFS and relapse incidence was observed between the two platforms, suggesting efficacy of both methods in childhood leukaemia (63).

A very comprehensive review and summary of the advantages and disadvantages of the three different approaches used in paediatric hHSCT has been done by Shah (64) and are summarized in Table 1. The Beijing GIAC method has the lowest risk of graft failure but has two disadvantages: namely a higher risk of GvHD and the need for the donor to undergo two stem collection procedures. Notably, GIAC hHSCT in children with haematological malignancies in CR1 has resulted in superior outcomes compared with transplants utilising umbilical cord blood from MUDs $(65,66)$. The John Hopkins' PTCy approach is easily applicable and has the lowest delivery cost yet carries a risk of graft failure risk of up to $15 \%$ as well as risks of sinusoidal obstruction syndrome (up to 20\%) and haemorrhagic cystitis (up to $35 \%)(35,37,64)$. T-cell-depleted HSCT is associated with a very low incidence of GvHD but has been reported to have a higher risk of viral infections. Moreover, ex vivo T-cell depletion is costly and requires sophisticated laboratory infrastructure.

The various studies discussed above have demonstrated that hHSCT is efficacious in children with ALL. Whilst some studies

TABLE 1 | Comparative features of the various hHSCT approaches used in treatment of children with haematological malignancies.

\begin{tabular}{llll}
\hline & TCR $\boldsymbol{\beta} \boldsymbol{\beta}$-depleted & PTCy & GIAC \\
\hline Conditioning & MAC or RIC & MAC or RIC & MAC \\
Stem cell source & PB & BM or PB & BM and PB \\
GVHD risk & Low & Low with BM & High \\
& & Moderate with PB & \\
Graft failure risk & Low & Moderate & Low \\
Cost & High & Low & Low/Moderate \\
Applicability & Sophisticated & Easy & Easy \\
& infrastructure needed & & \\
Viral infection risk & High & Moderate & Moderate
\end{tabular}

BM, bone marrow; GIAC, GCSF-Intensive immunosuppression-ATG-Combined stem cell source (Beijing protocol); GVHD, graft-vs. -host disease; MAC, myeloablative conditioning; $P B$, peripheral blood; PTCy, post-transplantation cyclophosphamide; RIC, reducedintensity conditioning; TCR $\alpha \beta$, T-cell receptor $\alpha \beta$. 
have demonstrated that matched donor HSCT has superior CIR and NRM in children with ALL, these differences are largely seen only in those in the very-high-risk category (1). Thus, hHSCT remains a feasible transplant option for children with ALL lacking a matched donor, although infections and GvHD remain significant challenges.

\section{OPTIMAL DONOR CHOICE IN HHSCT}

For the majority of children, two or more potential haploidentical donors are usually available. Studies using various hHSCT methods have reported dissimilar incidence of GvHD, TRM and relapse incidence using different preferred donors, thus raising the question of best donor choice for a specific hHSCT platform. Here, we review studies involving only children with ALL as well as studies in which adult ALL patients or children with various other haematologic malignancies were included to identify the best donor option for each hHSCT method.

A large study of 1,210 patients treated using the Beijing hHSCT platform in children and adults with haematological malignancies including ALL was conducted by Wang et al. (53). Younger donors and paternal donors were associated with better outcomes (lower NRM and better survival) when compared with older donors and maternal donors, respectively.

Transplants using sibling donors who did not share inherited maternal HLA antigens with the recipient (i.e., non-inherited maternal antigen [NIMA] mismatched) were associated with the lowest incidence of acute GvHD when compared with transplants using sibling donors who were non-inherited paternal antigen (NIPA) mismatched or parental donors. Thus, for hHSCT using the Beijing protocol, a NIMA-mismatched younger male sibling is the preferred donor followed by the father over the mother or a sister.

Optimal donor choice for children with ALL undergoing hHSCT-PTCy has largely been extrapolated from studies using adults, although some studies have included paediatric patients. These studies have alluded to an influence of donor age and gender on outcomes. Berger et al. reported that in 33 children and adolescents with various haematological malignancies who underwent hHSCT-PTCy, female patients and patients who had maternal or other female donors had a significantly lower risk of relapse than other patients (female vs. male patient: 7 vs. 35\%; female donor vs. male donor: 10 vs. $40 \%$; mother donor vs. other donor: 0 vs. $35 \%$, respectively) (34). In contrast, Kasamon et al. found that hHSCT-PTCy in male recipients with a female donor was associated with an inferior EFS compared with male recipients with a male donor (HR 1.47; $p=0.04$ ) (67). More recent paediatric studies have not confirmed selection criteria for the most ideal donor. However, donors of the same sex and with a similar $\mathrm{ABO}$ blood group and cytomegalovirus serostatus as the recipient are preferred, as are recipients with an absence of HLA antibodies to the donor. In an international study of 180 children with ALL who received hHSCT-PTCy, a multivariate analysis found that donor selection based on relationship to recipient did not affect NRM; instead, disease status at transplant, age $>13$ years and use of peripheral blood stem cell grafts were independent factors associated with decreased OS (46). Trujillo et al. reported on 26 children with ALL who received RIC followed by hHSCT-PTCy. The incidence of acute grade III-IV GvHD was $17 \%$, OS was $56 \%$, and EFS was $46 \%$, with no association between these outcomes and donor-recipient kinship (38).

The impact of donor selection has been more thoroughly investigated in hHSCT using T-cell-depleted grafts. In a study of 36 paediatric patients (17 AML, 19 ALL) who received haploidentical T-cell depleted $\left(\mathrm{CD} 34^{+}\right.$selected) grafts, the risk of relapse was best predicted by the presence of inhibitory KIR on the donor's NK cells and the absence of matching KIR ligand in the HLA repertoire of the recipient (68). In contrast to previously described ligand-ligand models, this was named a receptor-ligand model (or missing-self model); NK-cell alloreactivity based on this model more accurately predicted a lower risk of relapse. Additional factors that confer a reduced risk of relapse in children with ALL include the use of grafts from KIR haplotype B donors compared with KIR haplotype $\mathrm{A}$, and the presence of centromeric but absence of telomeric group B KIR haplotypes $(69,70)$. Taken together, these studies suggested that KIR genotyping is an important consideration for donor selection in T-cell-depleted hHSCT. Donor age and sex have also been recognised to influence transplant outcomes in this setting. A study of 94 paediatric patients with high-risk leukaemia who received $\mathrm{CD}^{+} / \mathrm{CD} 19^{+}$and $\mathrm{TCR} \alpha \mathrm{b}^{+} / \mathrm{CD} 19^{+}$ T-cell-depleted haploidentical grafts by Gonzalez-Vicent et al. demonstrated faster recovery of immune cells as well as lower NRM when using donors $<40$ years old (NRM: donor $>40$ years, $43 \%$; donor $<40$ years, $13 \%$; $p=0.006)(71)$. With regards to donor sex, a retrospective analysis of 118 patients with acute leukaemia which also included children who received T-celldepleted hHSCT after myeloablative conditioning by Stern et al. showed that donor sex in parental donor transplantation is an independent prognostic factor for survival (HR for father vs. mother 2.36; $p=0.003$ ) (72). However, donor sex had no influence on survival if the donor was a sibling. These data suggested a mother should be preferred as the parental donor in T-cell-depleted hHSCT.

In 2019, the EBMT published consensus recommendations for donor selection in hHSCT based on a comprehensive review of literature combining adult and childhood subjects (73). A summary of the recommendations provided for the two broad hHSCT groups, namely T-cell-depleted and T-cellreplete hHSCT (including PTCy and Beijing platforms), is shown in Table 2.

One ethical issue which remains to be resolved is the use of sibling donors who are minors (aged $<18$ years). This situation provides a potential conflict of interest for parents. Regulations are different between countries; in some countries, relevant laws do not exist. International standards published by the Foundation for the Accreditation of Cellular Therapy at the University of Nebraska Medical Centre (FACT) and Joint Accreditation Committee of the International Society for Cell and Gene Therapy and EBMT (JACIE) suggest using donor advocates who are not the transplant recipient's treating physician to represent the minor donors (74). The advocate would help the donor to understand the risks and benefits 
TABLE 2 | EBMT consensus recommendations for donor selection in hHSCT.

\begin{tabular}{|c|c|}
\hline T-cell-depleted hHSCT & T-cell-replete hHSCT \\
\hline $\begin{array}{l}\text { 1. For a recipient with donor-specific } \\
\text { anti-HLA antibodies, a donor without } \\
\text { the corresponding HLA antigen is } \\
\text { preferred (MFI <1,000) } \\
\text { 2. NK-cell alloreactive donor if } \\
\text { available } \\
\text { 3. Younger donor over older donor } \\
\text { 4. A male donor for a male recipient } \\
\text { 5. First-degree relative over } \\
\text { second-degree HLA-half-matched } \\
\text { donor } \\
\text { 6. Between parent donors, mother is } \\
\text { preferred over father } \\
\text { 7. ABO-matched donor } \\
\text { 8. CMV-seropositive donor for } \\
\text { CMV-seropositive recipient }\end{array}$ & $\begin{array}{l}\text { 1. For a recipient with donor-specific } \\
\text { anti-HLA antibodies, a donor without } \\
\text { the corresponding HLA antigen is } \\
\text { preferred (MFI <1,000) } \\
\text { 2. Younger donor over older donor } \\
\text { 3. A male donor for a male recipient } \\
\text { 4. Sibling or offspring donor over } \\
\text { parent donor } \\
\text { 5. Between parent donors, father is } \\
\text { preferred over mother donor } \\
\text { 6. An ABO-matched donor is preferred } \\
\text { to a minor ABO-mismatched donor, } \\
\text { and a minor ABO-mismatched } \\
\text { donor is preferred to major } \\
\text { ABO-mismatched donor. } \\
\text { 7. First-degree relative over second- } \\
\text { degree HLA-half-matched donor } \\
\text { (Beijing protocol) } \\
\text { 8. Donor with KIR ligand match } \\
\text { (Beijing protocol) } \\
\text { 9. Donor with NIMA mismatch over } \\
\text { NIPA mismatch (Beijing protocol) }\end{array}$ \\
\hline
\end{tabular}

Table modified from Ciurea et al. (73). MFI, mean fluorescence intensity; NK, natural killer; NIMA, non-inherited maternal antigens; NIPA, non-inherited paternal antigens.

of stem cell donation, try to resolve potential medical and psychological problems and obtain consent to donate without any pressure. A medical ethicist may also be involved to provide an unbiased assessment.

Related to this, grafts from HLA-haploidentical second-degree related donors (namely aunts, uncles and cousins) have also been successfully used for hHSCT involving both PTCy and Beijing approaches $(75,76)$. This is a feasible option if no suitable firstdegree relative is available (77) and may help to address ethical conflicts related to using minor siblings as donors.

\section{OPTIMAL CHOICE OF CONDITIONING REGIMEN IN hHSCT}

Different types of preparative regimens for the various hHSCT platforms have been proposed. Myeloablative conditioning has been more frequently utilised with the Beijing protocol and TCR $\alpha \beta$-CD19-depleted hHSCT approaches vs. RIC for patients with haematological malignancies. In the original hHSCT-PTCy method for adults with leukaemia, RIC was used but later studies employed myeloablative conditioning with better EFS and no significant increase in NRM or GvHD (64).

Several studies in children with ALL comparing TBI-based and chemotherapy-based myeloablation in the haploidentical setting have been published, and the results are mostly in favour of TBI. In the aforementioned study of 80 children with acute leukaemia who received myeloablation and TCR $\alpha \beta$ T-cell- and CD19-depleted hHSCT, Locatelli et al. reported that the use of TBI was associated with reduced incidence of relapse and better GRFS compared with the use of chemotherapy-based conditioning (30). In a study of 18 patients with high-risk paediatric haematological malignancies who underwent TCR $\alpha \beta$ depleted hHSCT, patients conditioned with TBI had superior OS (66 vs. $37 \%$, respectively; $p=0.05$ ) and EFS (61 vs. $33 \%$, respectively; $p=0.04$ ) compared with patients conditioned with chemotherapy only (33).

In another study, involving 42 children with ALL who received TCR $\alpha \beta$-depleted hHSCT, those who received TBI-based conditioning had a trend towards better EFS compared with those given treosulfan-based myeloablation (62.0 vs. $46.5 \%$, respectively), although this result did not reach statistical significance (32). In contrast to the above studies, Bertaina et al. reported on a study including 98 Italian children who received TCR $\alpha \beta$ T-cell- and CD19-depleted hHSCT; the type of myeloablative regimen employed (TBI based or chemotherapy based) did not influence LFS (27). To address the question of the best choice of conditioning for children with highrisk ALL, the For Omitting Radiation Under Majority age (FORUM) trial was launched in mid-2013. FORUM was a randomised, controlled, open-label multicentre trial involving 417 children with high-risk ALL who received myeloablative allogeneic HSCT. Among patients aged $>4$ years who received HLA-matched grafts, superior OS (91 vs. $75 \%$, respectively; $p$ $<0.0001)$ and lower relapse risk (12 vs. $33 \%$, respectively; $p<0.0001)$ were observed in those conditioned with myeloablative TBI plus etoposide compared with those receiving myeloablative chemoconditioning (thiotepa and fludarabine with either busulfan or treosulfan) (78). Patients who received HLAmismatched donor grafts, including from haploidentical donors or MUDs, were also observed. Preliminary results for this latter group of patients did not show any significant difference between TBI-based conditioning vs. chemo-conditioning with regard to OS, EFS, CIR or TRM, but final results are yet to be determined. In the series by Ruggeri et al. involving 139 children with ALL who received myeloablation followed by hHSCT-PTCy, relapse incidence at 2 years was higher in those receiving chemoconditioning compared with TBI (38 vs. 17\%, respectively; $p=$ not significant) (46). Notably, the relapse incidence for children who received RIC $(n=41)$ was similar to myeloablative chemotherapy (i.e., 38\% for both groups) whilst NRM was lowest in the children who received RIC compared with those who received myeloablative chemotherapy or TBI (7.7 vs. 17.5 vs. $18.4 \%$, respectively). These data, however, should be interpreted with caution as children who were selected to receive RIC may have clinical conditions precluding myeloablative chemo-conditioning and/or TBI, leading to bias. Comparative trials to assess RIC and myeloablative conditioning in patients eligible to receive either conditioning type are needed to determine the role of RIC regimens in hHSCT for childhood ALL.

\section{STRATEGIES TO IMPROVE hHSCT OUTCOME}

Progressive disease and infectious complications remain the leading causes of death after HSCT in paediatric ALL. 
Intervention strategies to reduce post-transplant relapse risk include improving conditioning regimens to exert more antineoplastic activity without additional toxicity, graft selection and engineering to augment GVL, and post-transplant chemotherapy to eliminate residual tumour cells (79). Newer strategies have focused on the modulation of donor-derived immune cells to harness the effect of GVL after transplant to prevent relapse without the side effects of GvHD. In some settings, adoptive immunotherapy has been used prophylactically, although this is more difficult to apply routinely as it is labour intensive and time consuming (80). In T-cell-depleted hHSCT, more advanced graft manipulation has been achieved with better understanding of pathophysiology in order to enhance the GVL effect.

Several mechanisms of leukaemia relapse have been described, and common to these is an acquired ability of malignant cells to escape immune surveillance through intrinsic or extrinsic driven processes. A well-described mechanism after HSCT involves tumour cells demonstrating copy neutral loss of heterozygosity of mismatched HLA haplotype on chromosome $6 \mathrm{p}$ by acquired somatic uniparental disomy, described as "genomic HLA loss" $(81,82)$. The resultant HLA alteration provides the tumour cells with the ability to evade patrolling donor $\mathrm{T}$ cells whose alloreactivity and overall GVL effect is mediated by the expression of mismatched HLA molecules on the surface of leukaemic cells. An important clinical implication for patients who develop HLA loss as a mechanism of relapse is the futility of administering additional donor $\mathrm{T}$ cells at relapse, given the lack of an HLA-mismatched target on tumour cells. Instead, a second allogeneic HSCT from a different donor would be useful to target the remaining HLA haplotype. Other relapse mechanisms that have been described include: (1) downregulation of HLA class II molecules, impairing the effects of donor T-cell alloreactivity that respond to HLA class II restricted peptides; (2) upregulation of inhibitory ligands by cancer cells, such as PD-L1 and B7-H3 (with the former associated with impairment of T-cell function); and (3) the release of immune-suppressive cytokines from tumour cells (IL-10, TGF-B) that upregulate the Treg population and inhibit T-cell and antigen-presenting cell function $(81,82)$.

The determinants for risk of relapse are multifactorial and dependent on various patient and treatment variables including biologic characteristics and disease risk before HSCT, conditioning intensity, and GvHD prophylaxis strategies. Additionally, issues to take into account include feasibility, tolerability and treatment toxicity, complications of opportunistic infections and GvHD (83). Targeted agents against an identified genomic mutation may be used as maintenance therapy to reduce residual tumour cells and prevent relapse after HSCT. Post-transplant use of a tyrosine kinase inhibitor against $B C R-A B L 1$ in patients with $\mathrm{Ph}^{+}$ALL may reduce the risk of relapse, but this is not a consistent finding (81). In a prospective, multicentre study from 2013 involving 55 adult patients with $\mathrm{Ph}+\mathrm{ALL}$ randomised to receive imatinib pre-emptively or prophylactically, low rates of relapse were observed in both groups regardless of timing of therapy, and no significant differences in overall outcomes were observed between groups (84). In 2016, the Acute Leukaemia Working Party of the EBMT issued a recommendation to support either prophylactic or pre-emptive tyrosine kinase inhibitor therapy in patients with $\mathrm{Ph}^{+}$ALL (85).

Unique to hHSCT is the opportunity to exploit donorrecipient immunocellular mismatches to enhance GVL effects. Cellular therapy may be polyclonal and non-specific, as is the case of donor lymphocyte infusion (DLI), or may be engineered to target specific leukaemic cells (Figure 1).

In DLI, non-tolerant donor $\mathrm{T}$ cells are harnessed to augment the GVL effect and thus reduce the risk of overt relapse in states of mixed chimerism or positive MRD in patients with haematological malignancies. However, the effectiveness of DLI is not uniform across all haematological malignancies: better efficacy has been demonstrated for low-risk disease malignancies such as CML, chronic lymphocytic leukaemia, or low-grade lymphoma compared with high-risk malignancies such as ALL and AML (86). The use of DLI has been particularly disappointing in ALL as it does not consistently induce remission and is associated with risks of acute GvHD in $40-60 \%$ of patients, resulting in significant mortality (87-89). As earlier stated, DLI is ineffective in patients who demonstrate genomic HLA loss as a mechanism of relapse, and thus testing for HLA loss in patients who have relapsed is useful prior to employing DLI therapy.

CAR T-cell therapy is an established form of immunotherapy for relapsed/refractory B-cell precursor ALL; it is capable of inducing high remission rates but is associated with poor longterm LFS in the adult population (89). CAR T-cell therapy consolidated with later HSCT is associated with more durable remission compared with CAR T-cell therapy alone (90, 91). In a study involving 110 high-risk ALL patients of whom 42 had MRD-positive disease, CAR T-cell therapy cleared MRD in all and $73.5 \%$ of patients subsequently underwent allogeneic HSCT with a resultant 1-year EFS of $76.9 \%$ (92). Paediatric patients and young adults with high-risk ALL, however, display better long-term remission compared with adults and without the need for HSCT consolidation, with a 1-year EFS of $50 \%$, calling into question which patients should be consolidated with HSCT after CAR T-cell therapy (93). In adults with high-risk ALL, Jiang et al. proposed several factors for consideration of consolidative HSCT after CAR T-cell therapy, including highrisk disease features pre CAR T-cell therapy, lymphodepletion without fludarabine, low persistence of CAR T-cells and Bcell recovery, and presence of a leukaemic sequence identified through next generation sequencing after CAR T-cell therapy (94). In the post-transplant setting, CAR T-cell therapy derived from either the donor or recipient may be used to treat relapse or used as prophylaxis against relapse. When applied to treat post-HSCT relapse, CAR T-cell therapy is able to induce high remission rates with a relatively low incidence of GvHD $(<10 \%)$. Newer methods of applying CAR T cells as prophylaxis against relapse after HSCT in patients with ALL have been attempted. In China, two adult patients with high-risk ALL received infusion of donor-derived CD19+_CAR T cells 60 days after hHSCT as prevention against relapse (95). One patient had attained MRDnegative remission prior to HSCT and was disease free 1 year after HSCT. The other patient had undergone HSCT without achieving CR status; this patient attained MRD negativity after HSCT and remained disease free for 6 months. The long-term 


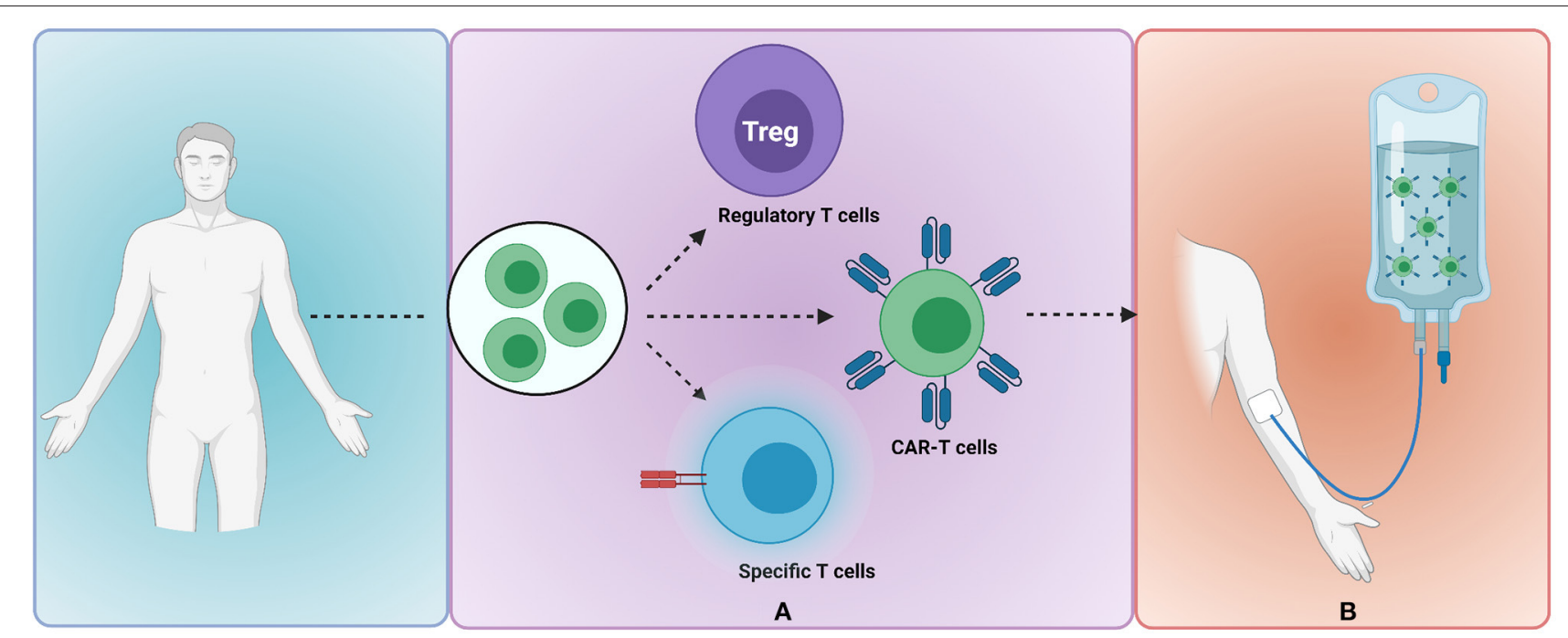

FIGURE 1 | Donor-recipient immunocellular therapy to mitigate risk of leukaemia relapse. (A) Donor-derived T cells are selected and undergo modification or engineering to produce clonally expanded T cells of a specified subset e.g., regulatory $T$ cells, CAR-T cells or $T$ cells with externally inducible safety switch (B) adoptive transfer of modified $T$ cells to the recipient. Image created with BioRender.com. CAR, chimeric antigen receptor.

outcome of prophylactic CAR T-cell therapy after HSCT remains to be seen. Presently, CAR T-cell therapy may be used as a bridge to HSCT in selected paediatric patients with high-risk ALL in order to attain MRD-negative status and a better subsequent LFS. Alternatively, CAR T cells may be applied in the post-transplant setting to treat disease relapse or as prophylaxis against relapse in those deemed at highest risk (92).

Treg infusion in HSCT is associated with a reduced risk of GvHD without an increased risk of relapse and with improved immune reconstitution. Tregs counteract the effector T-cell alloreactivity that contributes to GvHD without inhibiting conventional T-cell cytotoxicity against cancer cells (18). The first study to describe adoptive transfer of Tregs in humans involved 28 patients with high-risk malignancies (5 with ALL) who underwent hHSCT. In that study, Di Ianni et al. showed that infusion of thymic-derived $\mathrm{CD}^{+}{ }^{+} \mathrm{CD} 25^{+} \mathrm{FoxP}^{+}$Tregs on day -4 followed by $\mathrm{CD} 34^{+}$-selected peripheral blood stem cells and conventional T-cell infusion on day 0 eliminated GvHD without the use of post-transplant immunosuppression; it also improved immune recovery and was not associated with an increased risk of relapse (96). A follow-up study by Martelli in 2014 further showed that use of adoptive immunotherapy with Tregs and conventional $\mathrm{T}$ cells was associated with a significantly reduced CIR (5 vs. $>30 \%$, respectively), and a trend towards better survival compared with historical controls (18). The transfer of Tregs together with a T-cell-replete graft containing conventional $\mathrm{T}$ cells results in the reduced incidence of GvHD and CIR and faster immune reconstitution with a broad T-cell repertoire $(18,80,96)$. Tregs have not been associated with inhibition of general immunity or impaired responses to pathogens but rather promote stronger and faster immune reconstitution compared with historical controls $(18,80)$. The use of adoptive Treg transfer has also been associated with a broader
T-cell repertoire upon reconstitution, increased frequency of pathogen-specific CD4/CD8 at 2 months (97), and improved immunity to opportunistic pathogens (96).

Newer cellular engineering modalities have also enabled the development of donor $\mathrm{T}$ cells with improved specificity to accelerate engraftment and immune reconstitution, target leukaemic cells to reduce relapse risk, and improve infective immunity. To abrogate the risk of uncontrolled GvHD brought by donor $\mathrm{T}$ cell add-back, these cells may be transduced with a safety switch that is externally inducible in the event of GvHD. The first study to assess the efficacy of the inducible caspase 9 (iCasp9) suicide gene in hHSCT was by Di Stasi et al. In this study, five children who had undergone hHSCT for relapsed acute leukaemia received an infusion of donor $\mathrm{T}$ cells expressing iCasp9. Following iCasp 9 induction, more than $90 \%$ of the modified T cells were eliminated and there was rapid resolution of GvHD (98). Another study reported on the long-term outcome of HSCT with iCasp9-transduced T cells in 10 patients with haematological malignancies; these patients demonstrated longterm persistence of the modified $\mathrm{T}$ cells in vivo, with immune benefit that was conferred in both the early phase, by the infused cells themselves, and in the later phase, through rapid reconstitution of naïve $\mathrm{T}$ lymphocytes, thus providing sustained immune protection against viral pathogens (99).

In the setting of hHSCT, donor-recipient alloreactive NKcell mismatch can mediate killing of residual tumour cells through the presence of inhibitory receptors on single KIR donor NK cells that bind ligands present in the donor and absent in the recipient; this is known as the "missing self" theory $(100,101)$. As described earlier, NK-cell alloreactivity enhances anti-leukaemic effect without mediating GvHD. The clinical utility of NK-cell alloreactivity is dependent on the transplant platform used; more beneficial effects have been documented 
in the context of T-cell-depleted hHSCT for acute leukaemia rather than T-cell-replete hHSCT with PTCy, although data showing benefit have been more consistent for AML than ALL. Outcomes of NK-cell alloreactivity have a lesser impact in non-myeloablative-based hHSCT-PTCy due to the over-riding effects of T-cell immunosuppressive therapy. PTCy selectively and completely eliminates actively proliferating NK cells derived from the graft, impairs NK-cell recovery and maturation, and negates the overall impact of NK-cell KIR ligand mismatches on HSCT outcome (102).

An area of interest for future research is the use of specific cytokines to promote polyclonal expansion of haematopoietic stem cells to improve immune reconstitution, reduce rates of infection and reduce the risk of relapse. Infusion of mature donor alloreactive NK cells with the addition of IL-15 for in vivo expansion of NK cells reduces the incidence of relapse and viral infections (102). IL-15 promotes the expansion of T and B cells and the survival of NK cells as well as promoting the generation of $\mathrm{CD}^{+}$memory T cells (82). IL-2 given at low doses can promote the proliferation of T, B and NK cells and restore haemostasis of CD4 ${ }^{+} \mathrm{T}$ cells and Tregs, improving T-cell reconstitution and GVL effect without increased GvHD risk (97). Interferon alpha has direct anti-tumour activity, enhances NK-cell cytotoxicity and stimulates dendritic cells important in immune surveillance and the directed killing of malignant cells (82).

In summary, strategies incorporating cell- and immunebased immunotherapy after HSCT provide the opportunity to enhance GVL effect, reduce the risk of relapse, improve immune reconstitution, reduce rates of infection and reduce the risk of severe GvHD. Post-transplant maintenance chemotherapy, such as tyrosine kinase inhibitors in patients with $\mathrm{Ph}^{+} \mathrm{ALL}$, has also been shown to be useful.

\section{CONCLUSION}

hHSCT represents a promising therapeutic approach for children with ALL who require HSCT but lack an HLA-matched donor. The exponential increase in the use of hHSCT for haematological malignancies in the last 10 years has allowed more data to

\section{REFERENCES}

1. Dalle JH, Balduzzi A, Bader P, Pieczonka A, Yaniv I, Lankester A, et al. The impact of donor type on the outcome of pediatric patients with very high risk acute lymphoblastic leukemia. A study of the ALL SCT 2003 BFM-SG and 2007-BFM-International SG. Bone Marrow Transplant. (2021) 56:257-66. doi: 10.1038/s41409-020-01014-x

2. Eapen M, Rubinstein P, Zhang MJ, Stevens C, Kurtzberg J, Scaradavou A, et al. Outcomes of transplantation of unrelated donor umbilical cord blood and bone marrow in children with acute leukaemia: a comparison study. Lancet. (2007) 369:1947-54. doi: 10.1016/S0140-6736(07)60915-5

3. Rocha V, Locatelli F. Searching for alternative hematopoietic stem cell donors for pediatric patients. Bone Marrow Transplant. (2008) 41:20714. doi: 10.1038/sj.bmt.1705963

4. Smith AR, Wagner JE. Alternative haematopoietic stem cell sources for transplantation: place of umbilical cord blood. Br J Haematol. (2009) 147:246-61. doi: 10.1111/j.1365-2141.2009.07828.x

5. Passweg JR, Baldomero H, Chabannon C, Basak GW, Corbacioglu S, Duarte $\mathrm{R}$, et al. The EBMT activity survey on hematopoietic-cell transplantation and emerge from the paediatric ALL population to guide optimal management choices. Studies to date have shown comparable OS and EFS in children who have undergone hHSCT for ALL in CR1/CR2 with those who underwent HSCT from an MSD or MUD, although survival rates remain poor for those transplanted in advanced or active disease. Preparatory regimens containing TBI are currently recommended for children and adolescents with ALL based on the results of several large studies reporting superior EFS and CIR with TBI-based conditioning compared with chemo-conditioning alone. The criteria for selection of a haploidentical family donor according to the different transplant platforms used has been further refined with better understanding of the donor-recipient immune interactions that underpin the GVL effect and mediate GvHD. Strategies to reduce relapse risk after hHSCT have focused on newer cellular-based therapies to harness the GVL effect without increasing the incidence of GvHD and overall NRM. Lastly, the ability to perform HSCT with reasonably good outcomes, unrestricted by the HLA barrier, has significantly expanded donor choices and may address ethical issues related to using minor siblings as donors for children with ALL.

\section{AUTHOR CONTRIBUTIONS}

SA, TM, MY, and HA contributed to the concept and design of this review, to the assembly, analysis and interpretation of data, and to manuscript writing and final approval. All authors are accountable for all aspects of this work.

\section{FUNDING}

HA and SA are supported by University of Malaya IIRG Grant (No.021-2019).

\section{ACKNOWLEDGMENTS}

The authors thank the ALL SCTped Forum for support in developing this review paper and Hannah Bridges, HB Health Comms Limited, UK, for editorial assistance.

cellular therapy 2018: CAR-T's come into focus. Bone Marrow Transplant. (2020) 55:1604-13. doi: 10.1038/s41409-020-0826-4

6. Luznik L, O'Donnell PV, Symons HJ, Chen AR, Leffell MS, Zahurak $M$, et al. HLA-haploidentical bone marrow transplantation for hematologic malignancies using nonmyeloablative conditioning and high-dose, posttransplantation cyclophosphamide. Biol Blood Marrow Transplant. (2008) 14:641-50. doi: 10.1016/j.bbmt.2008. 03.005

7. Huang XJ. Haploidentical hematopoietic stem cell transplantation without in vitro T-cell-depletion for the treatment of hematologic diseases. Chimerism. (2013) 4:26-8. doi: 10.4161/chim.24070

8. Yanir AD, Martinez CA, Sasa G, Leung K, Gottschalk S, Omer B, et al. Current allogeneic hematopoietic stem cell transplantation for pediatric acute lymphocytic leukemia: Success, failure and future perspectives-a single-center experience, 2008 to 2016. Biol Blood Marrow Transplant. (2018) 24:1424-31. doi: 10.1016/j.bbmt.2018.03.001

9. Aversa F, Pierini A, Ruggeri L, Martelli MF, Velardi A. The evolution of T cell depleted haploidentical transplantation. Front Immunol. (2019) 10:2769. doi: 10.3389/fimmu.2019.02769 
10. Baumeister SHC, Rambaldi B, Shapiro RM, Romee R. Key aspects of the immunobiology of haploidentical hematopoietic cell transplantation. Front Immunol. (2020) 11:191. doi: 10.3389/fimmu.2020.00191

11. Borsotti C, Danzl NM, Nauman G, Holzl MA, French C, Chavez E, et al. HSC extrinsic sex-related and intrinsic autoimmune disease-related human B-cell variation is recapitulated in humanized mice. Blood Adv. (2017) 1:2007-18. doi: 10.1182/bloodadvances.2017006932

12. Blazar BR, Taylor PA, Noelle RJ, Vallera DA. CD4(+) T cells tolerized ex vivo to host alloantigen by anti-CD40 ligand (CD40L:CD154) antibody lose their graft-versus-host disease lethality capacity but retain nominal antigen responses. J Clin Invest. (1998) 102:473-82. doi: 10.1172/JCI3741

13. Saha A, O'Connor RS, Thangavelu G, Lovitch SB, Dandamudi DB, Wilson $\mathrm{CB}$, et al. Programmed death ligand-1 expression on donor $\mathrm{T}$ cells drives graft-versus-host disease lethality. J Clin Invest. (2016) 126:2642-60. doi: 10.1172/JCI85796

14. Zeiser R, Blazar BR. Acute graft-versus-host disease - biologic process, prevention, and therapy. $N$ Engl J Med. (2017) 377:2167-79. doi: 10.1056/NEJMra1609337

15. Divito SJ, Aasebo AT, Matos TR, Hsieh PC, Collin M, Elco CP, et al. Peripheral host $\mathrm{T}$ cells survive hematopoietic stem cell transplantation and promote graft-versus-host disease. J Clin Invest. (2020) 130:462436. doi: 10.1172/JCI129965

16. Jardine L, Cytlak U, Gunawan M, Reynolds G, Green K, Wang XN, et al. Donor monocyte-derived macrophages promote human acute graft-versushost disease. J Clin Invest. (2020) 130:4574-86. doi: 10.1172/JCI133909

17. Booth NJ, McQuaid AJ, Sobande T, Kissane S, Agius E, Jackson SE, et al. Different proliferative potential and migratory characteristics of human CD4+ regulatory $\mathrm{T}$ cells that express either CD45RA or CD45RO. J Immunol. (2010) 184:4317-26. doi: 10.4049/jimmunol.0903781

18. Martelli MF, Di Ianni M, Ruggeri L, Falzetti F, Carotti A, Terenzi A, et al. HLA-haploidentical transplantation with regulatory and conventional Tcell adoptive immunotherapy prevents acute leukemia relapse. Blood. (2014) 124:638-44. doi: 10.1182/blood-2014-03-564401

19. Boudreau JE, Hsu KC. Natural killer cell education in human health and disease. Curr Opin Immunol. (2018) 50:10211. doi: 10.1016/j.coi.2017.11.003

20. Simonetta F, Alvarez M, Negrin RS. Natural killer cells in graft-versus-host disease after allogeneic hematopoietic cell transplantation. Front Immunol. (2017) 8:465. doi: 10.3389/fimmu.2017.00465

21. Suck G, Linn YC, Tonn T. Natural killer cells for therapy of leukemia. Transfus Med Hemother. (2016) 43:89-95. doi: 10.1159/000445325

22. Ruggeri L, Capanni M, Mancusi A, Urbani E, Perruccio K, Burchielli E, et al. Alloreactive natural killer cells in mismatched hematopoietic stem cell transplantation. Blood Cells Mol Dis. (2004) 33:216-21. doi: 10.1016/j.bcmd.2004.08.005

23. Mancusi A, Ruggeri L, Urbani E, Pierini A, Massei MS, Carotti A, et al. Haploidentical hematopoietic transplantation from KIR ligand-mismatched donors with activating KIRs reduces nonrelapse mortality. Blood. (2015) 125:3173-82. doi: 10.1182/blood-2014-09-599993

24. Wanquet A, Bramanti S, Harbi S, Furst S, Legrand F, Faucher C, et al. Killer cell immunoglobulin-like receptor-ligand mismatch in donor versus recipient direction provides better graft-versustumor effect in patients with hematologic malignancies undergoing allogeneic $\mathrm{T}$ cell-replete haploidentical transplantation followed by posttransplant cyclophosphamide. Biol Blood Marrow Transplant. (2018) 24:549-54. doi: 10.1016/j.bbmt.2017.11.042

25. Aversa F, Tabilio A, Terenzi A, Velardi A, Falzetti F, Giannoni C, et al. Successful engraftment of T-cell-depleted haploidentical "three-loci" incompatible transplants in leukemia patients by addition of recombinant human granulocyte colony-stimulating factor-mobilized peripheral blood progenitor cells to bone marrow inoculum. Blood. (1994) 84:394855. doi: 10.1182/blood.V84.11.3948.bloodjournal84113948

26. Ciceri F, Labopin M, Aversa F, Rowe JM, Bunjes D, Lewalle P, et al. A survey of fully haploidentical hematopoietic stem cell transplantation in adults with high-risk acute leukemia: a risk factor analysis of outcomes for patients in remission at transplantation. Blood. (2008) 112:357481. doi: 10.1182/blood-2008-02-140095
27. Bertaina A, Zecca M, Buldini B, Sacchi N, Algeri M, Saglio F, et al. Unrelated donor vs HLA-haploidentical alpha/beta T-cell- and B-celldepleted HSCT in children with acute leukemia. Blood. (2018) 132:2594607. doi: 10.1182/blood-2018-07-861575

28. Erbey F, Akcay A, Atay D, Ovali E, Ozturk G. Comparison of outcomes after HLA-matched unrelated and alphabeta T-cell-depleted haploidentical hematopoietic stem cell transplantation for children with high-risk acute leukemia. Pediatr Transplant. (2018) 22:e13192. doi: 10.1111/petr.13192

29. Lang P, Feuchtinger T, Teltschik HM, Schwinger W, Schlegel P, Pfeiffer M, et al. Improved immune recovery after transplantation of tcralphabeta/CD19depleted allografts from haploidentical donors in pediatric patients. Bone Marrow Transplant. (2015) 50 Suppl 2:S6-10. doi: 10.1038/bmt.2015.87

30. Locatelli F, Merli P, Pagliara D, Li Pira G, Falco M, Pende D, et al. Outcome of children with acute leukemia given HLA-haploidentical HSCT after alphabeta T-cell and B-cell depletion. Blood. (2017) 130:67785. doi: 10.1182/blood-2017-04-779769

31. Lang PJ, Schlegel PG, Meisel R, Schiulz AS, Greil J, Bader P, et al. Safety and efficacy of tcralpha/beta and CD19 depleted haploidentical stem cell transplantation following reduced intensity conditioning in children: results of a prospective multicenter phase I/II clinical trial. Blood. (2017) 130(Suppl. 1):214. doi: 10.1182/blood.V130.Suppl_1.214.214

32. Shelikhova L, Shekhovtsova Z, Balashov D, Boyakova E, Muzalevskyi I, Gutovskaya E, et al. Tcr $\alpha \beta+/ \mathrm{CD} 19+$-depletion in hematopoietic stem cells transplantation from matched unrelated and haploidentical donors following treosulfan or TBI-based conditioning in pediatric acute lymphoblastic leukemia patients. Blood. (2016) 128:4672. doi: 10.1182/blood.V128.22.4672.4672

33. Jacoby E, Varda-Bloom N, Goldstein G, Hutt D, Churi C, Vernitsky $\mathrm{H}$, et al. Comparison of two cytoreductive regimens for alphabeta-Tcell-depleted haploidentical HSCT in pediatric malignancies: Improved engraftment and outcome with TBI-based regimen. Pediatr Blood Cancer. (2018) 65:26839. doi: 10.1002/pbc.26839

34. Berger M, Lanino E, Cesaro S, Zecca M, Vassallo E, Faraci M, et al. Feasibility and outcome of haploidentical hematopoietic stem cell transplantation with post-transplant high-dose cyclophosphamide for children and adolescents with hematologic malignancies: an AIEOP-GITMO retrospective multicenter study. Biol Blood Marrow Transplant. (2016) 22:902-9. doi: 10.1016/j.bbmt.2016.02.002

35. Hong KT, Kang HJ, Choi JY, Hong CR, Cheon JE, Park JD, et al. Favorable outcome of post-transplantation cyclophosphamide haploidentical peripheral blood stem cell transplantation with targeted busulfanbased myeloablative conditioning using intensive pharmacokinetic monitoring in pediatric patients. Biol Blood Marrow Transplant. (2018) 24:2239-44. doi: 10.1016/j.bbmt.2018.06.034

36. Sawada A, Shimizu M, Isaka K, Higuchi K, Mayumi A, Yoshimoto $\mathrm{Y}$, et al. Feasibility of HLA-haploidentical hematopoietic stem cell transplantation with post-transplantation cyclophosphamide for advanced pediatric malignancies. Pediatr Hematol Oncol. (2014) 31:754-64. doi: 10.3109/08880018.2014.961214

37. Klein OR, Buddenbaum J, Tucker N, Chen AR, Gamper CJ, Loeb D, et al. Nonmyeloablative haploidentical bone marrow transplantation with posttransplantation cyclophosphamide for pediatric and young adult patients with high-risk hematologic malignancies. Biol Blood Marrow Transplant. (2017) 23:325-32. doi: 10.1016/j.bbmt.2016.11.016

38. Trujillo AM, Karduss AJ, Suarez G, Perez R, Ruiz G, Cardona A, et al. Haploidentical hematopoietic stem cell transplantation with post-transplantation cyclophosphamide in children with highrisk leukemia using a reduced-intensity conditioning regimen and peripheral blood as the stem cell source. Transplant Cell Ther. (2021) 27:427.e1-e7. doi: 10.1016/j.jtct.2021.02.010

39. Saglio F, Berger M, Spadea M, Pessolano R, Carraro F, Barone M, et al. Haploidentical HSCT with post transplantation cyclophosphamide versus unrelated donor HSCT in pediatric patients affected by acute leukemia. Bone Marrow Transplant. (2021) 56:586-95. doi: 10.1038/s41409-020-01 063-2

40. Jaiswal SR, Chakrabarti A, Chatterjee S, Bhargava S, Ray K, O’Donnell P, et al. Haploidentical peripheral blood stem cell 
transplantation with post-transplantation cyclophosphamide in children with advanced acute leukemia with fludarabine-, busulfan-, and melphalan-based conditioning. Biol Blood Marrow Transplant. (2016) 22:499-504. doi: 10.1016/j.bbmt.2015.11.010

41. Symons HJ, Zahurak M, Cao Y, Chen A, Cooke K, Gamper C, et al. Myeloablative haploidentical BMT with posttransplant cyclophosphamide for hematologic malignancies in children and adults. Blood Adv. (2020) 4:3913-25. doi: 10.1182/bloodadvances.2020001648

42. Uygun V, Karasu G, Daloglu H, Ozturkmen S, Caki Kilic S, Hazar V, et al. Haploidentical hematopoietic stem cell transplantation with post-transplant high-dose cyclophosphamide in high-risk children: A single-center study. Pediatr Transplant. (2019) 23:e13546. doi: 10.1111/petr.13546

43. Yesilipek MA, Uygun V, Karasu G, Daloglu H, Dincer Z. Haploidentical hematopoietic stem cell transplantation with post-transplant high-dose cyclophosphamide in high-risk children: A single-center study. Pediatr Transplant. (2016) 20:417-23. doi: 10.1111/petr.12658

44. Katsanis E, Sapp LN, Reid SC, Reddivalla N, Stea B. T-Cell replete myeloablative haploidentical bone marrow transplantation is an effective option for pediatric and young adult patients with high-risk hematologic malignancies. Front Pediatr. (2020) 8:282. doi: 10.3389/fped.2020. 00282

45. Sharma A, Rastogi N, Chatterjee G, Kapoor R, Nivargi S, Yadav SP. Haploidentical stem cell transplantation with posttransplant cyclophosphamide for pediatric acute leukemia is safe and effective. $J$ Pediatr Hematol Oncol. (2020) 43:e1033-6. doi: 10.1097/MPH.00000000000 02030

46. Ruggeri A, Galimard JE, Paina O, Fagioli F, Tbakhi A, Yesilipek A, et al. Outcomes of unmanipulated haploidentical transplantation using post-transplant cyclophosphamide (PT-Cy) in pediatric patients with acute lymphoblastic leukemia. Transplant Cell Ther. (2021) 27:424.e19. doi: 10.1016/j.jtct.2021.01.016

47. Chiusolo P, Bug G, Olivieri A, Brune M, Mordini N, Alessandrino $\mathrm{PE}$, et al. A modified post-transplant cyclophosphamide regimen, for unmanipulated haploidentical marrow transplantation, in acute myeloid leukemia: a multicenter study. Biol Blood Marrow Transplant. (2018) 24:1243-9. doi: 10.1016/j.bbmt.2018.01.031

48. Raiola AM, Dominietto A, Ghiso A, Di Grazia C, Lamparelli T, Gualandi F, et al. Unmanipulated haploidentical bone marrow transplantation and posttransplantation cyclophosphamide for hematologic malignancies after myeloablative conditioning. Biol Blood Marrow Transplant. (2013) 19:11722. doi: 10.1016/j.bbmt.2012.08.014

49. Fuchs EJ. Does post-transplantation cyclophosphamide inhibit graft-versus-leukemia? Biol Blood Marrow Transplant. (2020) 10:e243-4. doi: 10.1016/j.bbmt.2020.08.010

50. Ruggeri A, Labopin M, Battipaglia G, Chiusolo P, Tischer J, Diez-Martin JL, et al. Timing of post-transplantation cyclophosphamide administration in haploidentical transplantation: a comparative study on behalf of the acute leukemia working party of the European Society for Blood and Marrow Transplantation. Biol Blood Marrow Transplant. (2020) 26:191522. doi: 10.1016/j.bbmt.2020.06.026

51. Liu D, Huang X, Liu K, Xu L, Chen H, Han W, et al. Haploidentical hematopoietic stem cell transplantation without in vitro $\mathrm{T}$ cell depletion for treatment of hematological malignancies in children. Biol Blood Marrow Transplant. (2008) 14:469-77. doi: 10.1016/j.bbmt.2008. 02.007

52. Liu DH, Xu LP, Liu KY, Wang Y, Chen H, Han W, et al. Longterm outcomes of unmanipulated haploidentical HSCT for paediatric patients with acute leukaemia. Bone Marrow Transplant. (2013) 48:151924. doi: 10.1038/bmt.2013.99

53. Wang Y, Chang YJ, Xu LP, Liu KY, Liu DH, Zhang XH, et al. Who is the best donor for a related HLA haplotype-mismatched transplant? Blood. (2014) 124:843-50. doi: 10.1182/blood-2014-03-563130

54. Mo XD, Tang BL, Zhang XH, Zheng CC, Xu LP, Zhu XY, et al. Comparison of outcomes after umbilical cord blood and unmanipulated haploidentical hematopoietic stem cell transplantation in children with high-risk acute lymphoblastic leukemia. Int J Cancer. (2016) 139:210615. doi: $10.1002 / \mathrm{ijc} .30249$
55. Xue YJ, Cheng YF, Lu AD, Wang Y, Zuo YX, Yan CH, et al. Allogeneic hematopoietic stem cell transplantation, especially haploidentical, may improve long-term survival for high-risk pediatric patients with Philadelphia chromosome-positive acute lymphoblastic leukemia in the tyrosine kinase inhibitor era. Biol Blood Marrow Transplant. (2019) 25:1611-20. doi: 10.1016/j.bbmt.2018.12.007

56. Xue YJ, Suo P, Huang XJ, Lu AD, Wang Y, Zuo YX, et al. Superior survival of unmanipulated haploidentical haematopoietic stem cell transplantation compared with intensive chemotherapy as post-remission treatment for children with very high-risk Philadelphia chromosome negative B-cell acute lymphoblastic leukaemia in first complete remission. Br J Haematol. (2020) 188:757-67. doi: 10.1111/bjh.16226

57. Ji SQ, Chen HR, Yan HM, Wang HX, Liu J, Zhu PY, et al. Anti-CD25 monoclonal antibody (basiliximab) for prevention of graft-versushost disease after haploidentical bone marrow transplantation for hematological malignancies. Bone Marrow Transplant. (2005) 36:349-54. doi: 10.1038/sj.bmt.1705046

58. Di Bartolomeo P, Santarone S, De Angelis G, Picardi A, Cudillo L, Cerretti $\mathrm{R}$, et al. Haploidentical, unmanipulated, G-CSF-primed bone marrow transplantation for patients with high-risk hematologic malignancies. Blood. (2013) 121:849-57. doi: 10.1182/blood-2012-08-453399

59. Wang Y, Wu DP, Liu QF, Xu LP, Liu KY, Zhang XH, et al. Low-dose posttransplant cyclophosphamide and anti-thymocyte globulin as an effective strategy for GVHD prevention in haploidentical patients. J Hematol Oncol. (2019) 12:88. doi: 10.1186/s13045-019-0781-y

60. Ruggeri A, Sun Y, Labopin M, Bacigalupo A, Lorentino F, Arcese $\mathrm{W}$, et al. Post-transplant cyclophosphamide versus anti-thymocyte globulin as graft- versus-host disease prophylaxis in haploidentical transplant. Haematologica. (2017) 102:401-10. doi: 10.3324/haematol.2016.1 51779

61. Tang F, Xu Y, Chen H, Xu L, Zhang X, Wang Y, et al. Comparison of the clinical outcomes of hematologic malignancies after myeloablative haploidentical transplantation with G-CSF/ATG and posttransplant cyclophosphamide: results from the Chinese Bone Marrow Transplantation Registry Group (CBMTRG). Sci China Life Sci. (2020) 63:571-81. doi: 10.1007/s11427-019-9594-7

62. Dufort G, Castillo L, Pisano S, Castiglioni M, Carolina P, Andrea I, et al. Haploidentical hematopoietic stem cell transplantation in children with high-risk hematologic malignancies: outcomes with two different strategies for GvHD prevention. Ex vivo T-cell depletion and post-transplant cyclophosphamide: 10 years of experience at a single center. Bone Marrow Transplant. (2016) 51:1354-60. doi: 10.1038/bmt.2016.161

63. Perez-Martinez A, Ferreras C, Pascual A, Gonzalez-Vicent M, Alonso L, Badell I, et al. Haploidentical transplantation in high-risk pediatric leukemia: A retrospective comparative analysis on behalf of the Spanish working Group for bone marrow transplantation in children (GETMON) and the Spanish Grupo for hematopoietic transplantation (GETH). Am J Hematol. (2020) 95:28-37. doi: 10.1002/ajh.25661

64. Shah RM. Contemporary haploidentical stem cell transplant strategies in children with hematological malignancies. Bone Marrow Transplant. (2021) 56:1518-34. doi: 10.1038/s41409-021-01246-5

65. Apperley J, Niederwieser D, Huang XJ, Nagler A, Fuchs E, Szer J, et al. Haploidentical hematopoietic stem cell transplantation: a global overview comparing Asia, the European Union, and the United States. Biol Blood Marrow Transplant. (2016) 22:23-6. doi: 10.1016/j.bbmt.2015.11.001

66. Bashey A, Zhang X, Jackson K, Brown S, Ridgeway M, Solh M, et al. Comparison of outcomes of hematopoietic cell transplants from Treplete haploidentical donors using post-transplantation cyclophosphamide with 10 of 10 HLA-A, -B, -C, -DRB1, and -DQB1 allele-matched unrelated donors and HLA-identical sibling donors: a multivariable analysis including disease risk index. Biol Blood Marrow Transplant. (2016) 22:12533. doi: 10.1016/j.bbmt.2015.09.002

67. Kasamon YL, Luznik L, Leffell MS, Kowalski J, Tsai HL, Bolanos-Meade J, et al. Nonmyeloablative HLA-haploidentical bone marrow transplantation with high-dose posttransplantation cyclophosphamide: effect of HLA disparity on outcome. Biol Blood Marrow Transplant. (2010) 16:4829. doi: 10.1016/j.bbmt.2009.11.011 
68. Leung W, Iyengar R, Turner V, Lang P, Bader P, Conn P, et al. Determinants of antileukemia effects of allogeneic NK cells. J Immunol. (2004) 172:64450. doi: 10.4049/jimmunol.172.1.644

69. Babor F, Peters C, Manser AR, Glogova E, Sauer M, Potschger U, et al. Presence of centromeric but absence of telomeric group B KIR haplotypes in stem cell donors improve leukaemia control after HSCT for childhood ALL. Bone Marrow Transplant. (2019) 54:184758. doi: 10.1038/s41409-019-0543-z

70. Oevermann L, Michaelis SU, Mezger M, Lang P, Toporski J, Bertaina A, et al. KIR B haplotype donors confer a reduced risk for relapse after haploidentical transplantation in children with ALL. Blood. (2014) 124:27447. doi: 10.1182/blood-2014-03-565069

71. Gonzalez-Vicent M, Molina B, Deltoro N, Sevilla J, Vicario JL, Castillo A, et al. Donor age matters in T-cell depleted haploidentical hematopoietic stem cell transplantation in pediatric patients: Faster immune reconstitution using younger donors. Leuk Res. (2017) 57:60-4. doi: 10.1016/j.leukres.2017. 03.001

72. Stern M, Ruggeri L, Mancusi A, Bernardo ME, de Angelis C, Bucher C, et al. Survival after T cell-depleted haploidentical stem cell transplantation is improved using the mother as donor. Blood. (2008) 112:29905. doi: 10.1182/blood-2008-01-135285

73. Ciurea SO, Al Malki MM, Kongtim P, Fuchs EJ, Luznik L, Huang XJ, et al. The European Society for Blood and Marrow Transplantation (EBMT) consensus recommendations for donor selection in haploidentical hematopoietic cell transplantation. Bone Marrow Transplant. (2020) 55:1224. doi: 10.1038/s41409-019-0499-z

74. FACT-JACIE. International Standards for Hematopoietic Cellular Therapy Production Collection, Processing, and Administration. Eighth ed. FACT and JACIE (2021).

75. Elmariah H, Kasamon YL, Zahurak M, Macfarlane KW, Tucker N, Rosner GL, et al. Haploidentical bone marrow transplantation with posttransplant cyclophosphamide using non-first-degree related donors. Biol Blood Marrow Transplant. (2018) 24:1099-102. doi: 10.1016/j.bbmt.2018. 02.005

76. Zhang YY, Liu DH, Liu KY, Xu LP, Chen H, Han W, et al. HLA-haploidentical hematopoietic SCT from collateral related donors without in vitro T-cell depletion for hematological malignancies. Bone Marrow Transplant. (2014) 49:496-501. doi: 10.1038/bmt.2013.223

77. Garnier A, Guillaume T, Peterlin P, Bene MC, Le Bris Y, Dubruille V, et al. Second-degree relative donors for T-replete haploidentical allogeneic stem cell transplantation with high-dose post-transplant cyclophosphamide: toward crossing the major HLA barrier. Bone Marrow Transplant. (2017) 52:1063-4. doi: 10.1038/bmt.2017.60

78. Peters C, Dalle JH, Locatelli F, Poetschger U, Sedlacek P, Buechner J, et al. Total body irradiation or chemotherapy conditioning in childhood ALL: a multinational, randomized, noninferiority phase III study. J Clin Oncol. (2021) 39:295-307. doi: 10.1200/JCO.20.02529

79. Kekre N, Koreth J. Novel strategies to prevent relapse after allogeneic haematopoietic stem cell transplantation for acute myeloid leukaemia and myelodysplastic syndromes. Curr Opin Hematol. (2015) 22:11622. doi: $10.1097 / \mathrm{MOH} .0000000000000116$

80. Reisner Y, Hagin D, Martelli MF. Haploidentical hematopoietic transplantation: current status and future perspectives. Blood. (2011) 118:6006-17. doi: 10.1182/blood-2011-07-338822

81. O'Neill AT, Chakraverty R. Graft versus leukemia: current status and future perspectives. J Clin Oncol. (2021) 39:361-72. doi: 10.1200/JCO.20.01801

82. Rovatti PE, Gambacorta V, Lorentino F, Ciceri F, Vago L. Mechanisms of leukemia immune evasion and their role in relapse after haploidentical hematopoietic cell transplantation. Front Immunol. (2020) 11:147. doi: $10.3389 /$ fimmu.2020.00147

83. Soiffer RJ. Maintenance therapy for high-risk acute leukemia after allogeneic hematopoietic cell transplantation: wait a minute. Blood Adv. (2020) 4:3205-8. doi: 10.1182/bloodadvances.2019000389

84. Pfeifer H, Wassmann B, Bethge W, Dengler J, Bornhauser M, Stadler $\mathrm{M}$, et al. Randomized comparison of prophylactic and minimal residual disease-triggered imatinib after allogeneic stem cell transplantation for BCRABL1-positive acute lymphoblastic leukemia. Leukemia. (2013) 27:125462. doi: $10.1038 /$ leu.2012.352
85. Giebel S, Czyz A, Ottmann O, Baron F, Brissot E, Ciceri F, et al. Use of tyrosine kinase inhibitors to prevent relapse after allogeneic hematopoietic stem cell transplantation for patients with Philadelphia chromosomepositive acute lymphoblastic leukemia: A position statement of the Acute Leukemia Working Party of the European Society for Blood and Marrow Transplantation. Cancer. (2016) 122:2941-51. doi: 10.1002/cncr.30130

86. Dietz AC, Wayne AS. Cells to prevent/treat relapse following allogeneic stem cell transplantation. Hematology Am Soc Hematol Educ Program. (2017) 2017:708-15. doi: 10.1182/asheducation-2017.1.708

87. El-Jurdi N, Reljic T, Kumar A, Pidala J, Bazarbachi A, Djulbegovic B, et al. Efficacy of adoptive immunotherapy with donor lymphocyte infusion in relapsed lymphoid malignancies. Immunotherapy. (2013) 5:45766. doi: 10.2217/imt.13.31

88. Smith M, Zakrzewski J, James S, Sadelain M. Posttransplant chimeric antigen receptor therapy. Blood. (2018) 131:104552. doi: 10.1182/blood-2017-08-752121

89. Zhang LN, Song Y, Liu D. CD19 CAR-T cell therapy for relapsed/refractory acute lymphoblastic leukemia: factors affecting toxicities and long-term efficacies. J Hematol Oncol. (2018) 11:41. doi: 10.1186/s13045-018-0593-5

90. Hay KA, Gauthier J, Hirayama AV, Voutsinas JM, Wu Q, Li D, et al. Factors associated with durable EFS in adult B-cell ALL patients achieving MRD-negative CR after CD19 CAR T-cell therapy. Blood. (2019) 133:165263. doi: 10.1182/blood-2018-11-883710

91. Jiang H, Li C, Yin P, Guo T, Liu L, Xia L, et al. Anti-CD19 chimeric antigen receptor-modified T-cell therapy bridging to allogeneic hematopoietic stem cell transplantation for relapsed/refractory B-cell acute lymphoblastic leukemia: An open-label pragmatic clinical trial. Am J Hematol. (2019) 94:1113-22. doi: 10.1002/ajh.25582

92. Zhang X, Lu XA, Yang J, Zhang G, Li J, Song L, et al. Efficacy and safety of anti-CD19 CAR T-cell therapy in 110 patients with B-cell acute lymphoblastic leukemia with high-risk features. Blood Adv. (2020) 4:232538. doi: 10.1182/bloodadvances.2020001466

93. Gardner RA, Finney O, Annesley C, Brakke H, Summers C, Leger K, et al. Intent-to-treat leukaemia remission by CD19 CAR T-cells of defined formulation and dose in children and young adults. Blood. (2017) 129:332231. doi: 10.1182/blood-2017-02-769208

94. Jiang $\mathrm{H}, \mathrm{Hu} \mathrm{Y}, \mathrm{Mei} \mathrm{H}$. Consolidative allogeneic hematopoietic stem cell transplantation after chimeric antigen receptor T-cell therapy for relapsed/refractory B-cell acute lymphoblastic leukemia: who? When? Why? Biomark Res. (2020) 8:66. doi: 10.1186/s40364-020-00247-8

95. Zhang C, Ma YY, Liu J, Liu Y, Gao L, Gao L, et al. Preventive infusion of donor-derived CAR-T cells after haploidentical transplantation: Two cases report. Medicine. (2019) 98:e16498. doi: 10.1097/MD.0000000000016498

96. Di Ianni M, Falzetti F, Carotti A, Terenzi A, Castellino F, Bonifacio E, et al. Tregs prevent GVHD and promote immune reconstitution in HLA-haploidentical transplantation. Blood. (2011) 117:3921-8. doi: 10.1182/blood-2010-10-311894

97. de Koning C, Nierkens S, Boelens JJ. Strategies before, during, and after hematopoietic cell transplantation to improve T-cell immune reconstitution. Blood. (2016) 128:2607-15. doi: 10.1182/blood-2016-06-724005

98. Di Stasi A, Tey SK, Dotti G, Fujita Y, Kennedy-Nasser A, Martinez C, et al. Inducible apoptosis as a safety switch for adoptive cell therapy. N Engl J Med. (2011) 365:1673-83. doi: 10.1056/NEJMoa1106152

99. Zhou X, Di Stasi A, Tey SK, Krance RA, Martinez C, Leung KS, et al. Long-term outcome after haploidentical stem cell transplant and infusion of T cells expressing the inducible caspase 9 safety transgene. Blood. (2014) 123:3895-905. doi: 10.1182/blood-2014-01-551671

100. Mancusi A, Ruggeri L, Velardi A. Haploidentical hematopoietic transplantation for the cure of leukemia: from its biology to clinical translation. Blood. (2016) 128:2616-23. doi: 10.1182/blood-2016-07-730564

101. Ruggeri L, Capanni M, Casucci M, Volpi I, Tosti A, Perruccio $\mathrm{K}$, et al. Role of natural killer cell alloreactivity in HLAmismatched hematopoietic stem cell transplantation. Blood. (1999) 94:333-9. doi: 10.1182/blood.V94.1.333.413a31_333_339

102. Russo A, Oliveira G, Berglund S, Greco R, Gambacorta V, Cieri N, et al. NK cell recovery after haploidentical HSCT with posttransplant cyclophosphamide: dynamics and clinical implications. Blood. (2018) 131:247-62. doi: 10.1182/blood-2017-05-780668 
Conflict of Interest: The authors declare that the research was conducted in the absence of any commercial or financial relationships that could be construed as a potential conflict of interest.

The handling editor declared a shared consortium with several of the authors HA and TM at time of review.

Publisher's Note: All claims expressed in this article are solely those of the authors and do not necessarily represent those of their affiliated organizations, or those of the publisher, the editors and the reviewers. Any product that may be evaluated in this article, or claim that may be made by its manufacturer, is not guaranteed or endorsed by the publisher.

Copyright $(02022$ Ab Rahman, Matic, Yordanova and Ariffin. This is an open-access article distributed under the terms of the Creative Commons Attribution License (CC $B Y)$. The use, distribution or reproduction in other forums is permitted, provided the original author(s) and the copyright owner(s) are credited and that the original publication in this journal is cited, in accordance with accepted academic practice. No use, distribution or reproduction is permitted which does not comply with these terms. 